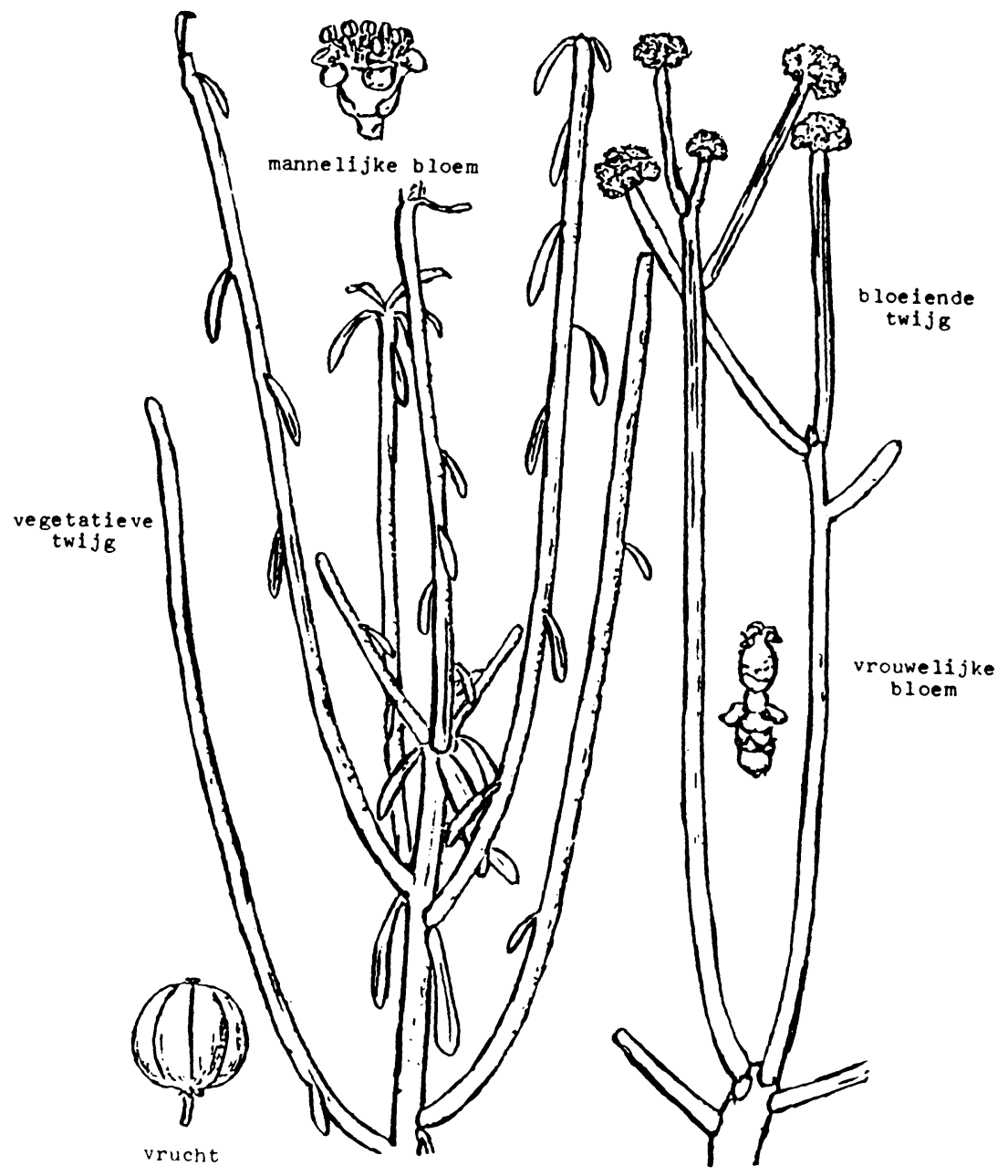

Figuur 1: Euphorbia tirucalli (naar Van Damme, 1989) 


\title{
HET TRADITIONEEL GEBRUIK VAN EUPHORBIA TIRUCALLI
}

\author{
Patrick Van Damme \\ Tropische Landbouw (RUG) \\ Coupure Links 653 \\ B-9000 Gent
}

ONDERZOEKSVELD: Projectevaluatie, plantenfysiologie, tropische plantenteelt

\section{SUMMARY}

\section{TRADITIONAL USES OF EUPHORBIA TIRUCALLI}

This article reviews the traditional uses of $\mathrm{E}$. tirucalli. This succulent latex plant, although originating from southern Africa, is now growing as a hedge plant in tropical and subtropical regions all over the world. Its special chemical properties have induced people to use it as a source of poison against bacteria, amoebas, nematodes, insects, fish, birds and mammals. Its medicinal use has also been recorded in a wide variety of settings. In a few cases, the latex has been used for the production of varnish and paint.

KEY WORDS: ethnobotany, latex, rubber, poisonous plants

\section{INLEIDING}

Euphorbia tirucalli L. (figuur 1) is een vrij droogte resistente plant die men op heel wat plaatsen in de tropische en subtropische wereld aantreft.

Het woord euphorbia is wellicht afgeleid van het Grieks euphorbos dat goed gevoed, dik, vet betekent en als plantenaam verwijst naar de dikke, succulente 
stengels die men dikwijls aantreft bij dit geslacht. Plinius (vermeld door Davidson en Rochford, 1976) en Berhaut (1975) hebben een kleurrijker verhaal. Volgens hen is de naam euphorbia afgeleid van de naam van de Numidische lijfarts van koning Juba II van Mauretanië (52 v.C. - 24 n.C.). Deze Euphorbus zou de eerste geweest zijn om kruiden van het geslacht Euphorbia in de farmacopee te gebruiken. Uit dank voor de bewezen diensten (die kruiden hadden dus blijkbaar nog effect ook) schreef koning Juba een verhandeling "De Euphorbia herba" waarin de eigenschappen van een plant, die waarschijnlijk Euphorbia resinifera was, beschreven worden (Davidson en Rochford, 1976). Deze plant produceerde een harsachtig produkt, het euphorbium (Henke, 1886), dat vroeger in Marokko verhandeld werd (De Conno et al., 1929).

Rond de soortnaam tirucalli kan men korter zijn. Deze is afgeleid van de Malabar-benaming (Indië) Tiru-calli (White et al., 1941; Berhaut, 1975).

De plant zou afkomstig zijn uit Zuid-Oost-Afrika, alhoewel Leach (1973) ook Angola niet uitsluit als mogelijk oorsprongsgebied. De meeste auteurs houden het echter bij het gebied wat nu overeenkomt met Tanzania en Kenia.

2000 jaar geleden zou E. tirucalli in Zuid-Afrika zijn binnengebracht door migrerende Bantoes die de plant als haagplant gebruikten en bovendien dachten dat hij een goed bliksemafleider was (Moll, 1978).

Vanuit deze zone in zuidelijk Afrika verspreidde de plant zich over bijna alle tropische en subtropische landen van de Oude Wereld. In Amerika is E. tirucalli maar voor een klein aantal plaatsen beschreven.

E. tirucalli dankt zijn cosmopolitisch voorkomen aan het gemak waarmee men hem kan vermenigvuldigen. Een stengelstukje van een aantal $\mathrm{cm}$ volstaat meestal. Na een paar weken worden wortels gevormd. Als de klimaatomstandigheden niet te slecht zijn, groeit daaruit een struik of boom die tot $7 \mathrm{~m}$ hoog kan worden.

De speciale eigenschappen en eigenaardige groeivormen van $\underline{E}$. tirucalli hebben voor gevolg gehad dat hij bij veel volkeren traditioneel voor tal van doeleinden gebruikt werd en wordt. Recent onderzoek heeft daar nog enkele nieuwe toepassingen aan toegevoegd. In dit artikel zal vooral op het eerste 
aspect worden ingegaan. De meer recente ontwikkelingen zullen in een tweede artikel behandeld worden. In beide gevallen wordt een bijzondere aandacht besteed aan het voorkomen en gebruik van de plant in Afrika. Voor de volledigheid zal er ook aangegeven worden wat er in Amerika en Azië op dit vlak te vinden valt.

Voor de meer botanische, fysiologische en landbouwkundige aspecten van deze interessante plant zij verwezen naar Van Damme (1989).

\section{TRADITIONEEL GEBRUIK VAN EUPHORBIA TIRUCALLI}

\subsection{HAAGPLANT}

E. tirucalli wordt in heel wat landen als haagplant gebruikt: Brazilië (Jurberg et al., 1985), Senegal (Kerharo \& Adam, 1974; Berhaut, 1975; Prot, persoonlijke mededeling; Van Damme, eigen waameming), Indië (Chopra et al., 1941; Badhwar et al., 1946; Gupta \& Mahadevan, 1967; Dey \& Fernandez, 1968; Mitchell \& Rook, 1979), Rwanda (Balasubramanian \& Egli, 1989; Counet, persoonlijke mededeling), Kenia (Bradley et al., 1985), Tanzania (Raymond, 1936), Zuid-Afrika (Burtt-Davy \& Stent, 1913; White et al., 1941), Zimbabwe (Watt \& Breyer-Brandwijk, 1962; Mitchell \& Rook (1979) noemen het er "rubber hedge"), Malawi (Mitchell \& Rook, 1979), West-Australië (Mitchell \& Rook, 1979), het Verre Oosten (juiste locatie niet gespecificeerd; Moll, 1978) en Indonesië (in pagers, ook pagars of paggers genoemd, wat afsluiting betekent; Heyne, 1927).

Het veelvuldig gebruik in hagen heeft te maken met de eigenschap van $\mathrm{E}$. tirucalli om na het stekken snel wortel te schieten en heel vlug heel dichte opstanden te vormen. Dit wordt vooral gewaardeerd in gebieden waar prikkeldraad onbestaande of onbetaalbaar is, en waar afsluitingen in dood materiaal, zoals hout, moeilijk te maken zijn omdat het hout er schaars is of snel opgevreten wordt door termietenkolonies. Bovendien zullen de takjes bij afbreken irriterende latex vrijgeven die inwerkt op de ogen en huid van mens (plunderaars en veedieven) en dier. Dit blijkt een goed afstotingsmechanisme te zijn. 
Dit laatste aspect werd heel goed geillustreerd in de film "The Gods Must Be Crazy I" (van Jamie Uys, Botswana 1980). Wanneer de blanke hoofdrolspeler (Marius Weyers) op een bepaald moment in het nauw gedreven wordt, vindt hij er niks beters op dan een paar schoten te lossen in een E. candelabrumboom waaronder zijn tegenstander zich verscholen heeft. De latexvloei die hier op volgt, is zo overvloedig en irriterend dat zijn belager alle wapens moet laten vallen (om zich te krabben) en er voor hem niets anders meer opzit dan zich over te geven...

De bevolking plant de hagen niet alleen rond het erf, maar ook rond kralen, graasweiden en velden.

Dey \& Fernandez (1968) raden aan om de planten regelmatig te snoeien omdat er anders onderaan in de vegetatie gaten ontstaan. Is dit laatste toch het geval dan kan men ze opvullen met E. antiquorum-planten.

In Malawi plant men de E.tirucalli op en rond begraafplaatsen om er de dieren weg te houden (Mitchell \& Rook, 1979). In Indië vormden de hagen een obstakel voor de kavalerie van het Engelse koloniale leger. Ze stonden, en staan, er rond de velden en langs de weg (Mitchell \& Rook, 1979).

Runderen, en ander grootvee, hebben een afkeer van deze plant. Dat is maar goed ook, want anders zou het weinig zin hebben om er hagen mee aan te leggen. Nochtans is het bekend dat geiten bij gebrek aan alternatieven soms E. tirucalli als voedsel gebruiken, vooral in het droog seizoen, (Moll, 1978). Ook in Kenia heeft men dit vastgesteld. Daar aten de geiten ook in het regenseizoen van de E. tirucalli. Wat opviel was dat blijkbaar niet alle geitenrassen dit deden, en dat het ook afhing van de streek of er al of niet van gegeten werd (Roman, persoonlijke mededeling). Wanneer koeien E. tirucalli opeten, kunnen diarree en kolieken als negatieve bijeffecten optreden (Raymond, 1936). 


\subsection{MEDICINAAL GEBRUIK}

\subsubsection{Spijsvertering}

Tegen buikwaterzucht (ascites), oedemen en hardnekkige constipaties kan het goed zijn om 3 a 4 latexdruppels op te lossen in palmwijn, of ze te mengen met een volledig, opgeklopt ei, of ze te vermengen met een spinazie van Hibiscus sabdariffa (figuur 2; Berhaut 1975).

Het latex-ei mengsel wordt ook gebruikt als purgeermiddel (Van Giffen, 1924; Raymond, 1939), tegen maagpijn en als braakmiddel (Van Giffen, 1924). Ook Heyne (1927) vermeldt het gebruik van "enkele latexdruppels met een geklopt ei gemengd" als purgans. Aftreksels van de wortels en jonge takjes worden ook met dit doel gebruikt.

Overdadig gebruik schaadt echter. Raymond (1936 en 1939; Tanzania) beschrijft symptomen van gastro-intestinitis die de dood als gevolg had. In éen geval was er zelfs sprake van een geperforeerde maag na de consumptie van E. tirucalli-latex. Bij dezelfde patiënt waren ook de darmen en nieren aangetast. Watt \& Breyer-Brandwijk (1962; zuidelijk Afrika) geven een voorbeeld van gastro-intestinale bloedingen met dodelijke afloop na opname van latex om steriliteit te behandelen. Soms is de vergiftiging een gevolg van het gebruik van de latex bij de visvangst (zie verder).

In Indië gebruikt men de latex als purgeermiddel en "counter- irritant" in de behandeling van dieren (Burtt-Davy \& Stent, 1913 en Chopra, 1933). In Indië wordt het ook als purgeermiddel voor mensen gebruikt, en tevens voor de behandeling van reuma, tandpijn en zenuwpijnen (neuralgia; Khan et al., 1987).

\subsubsection{Huid}

Niettegenstaande de latex huidirritaties opwekt, wordt hij in Senegal toch gebruikt om bepaalde huidziekten (schimmelinfecties?) te behandelen. Ook verse wonden zouden er vlugger mee helen (Berhaut, 1975). Heyne (1927) meldt het gebruik van het melksap als uitwendig geneesmiddel op schurftplekken en zweren. In Indië en Brazilië wordt de plant tegen wratten gebruikt (Kinghom, 1979). 


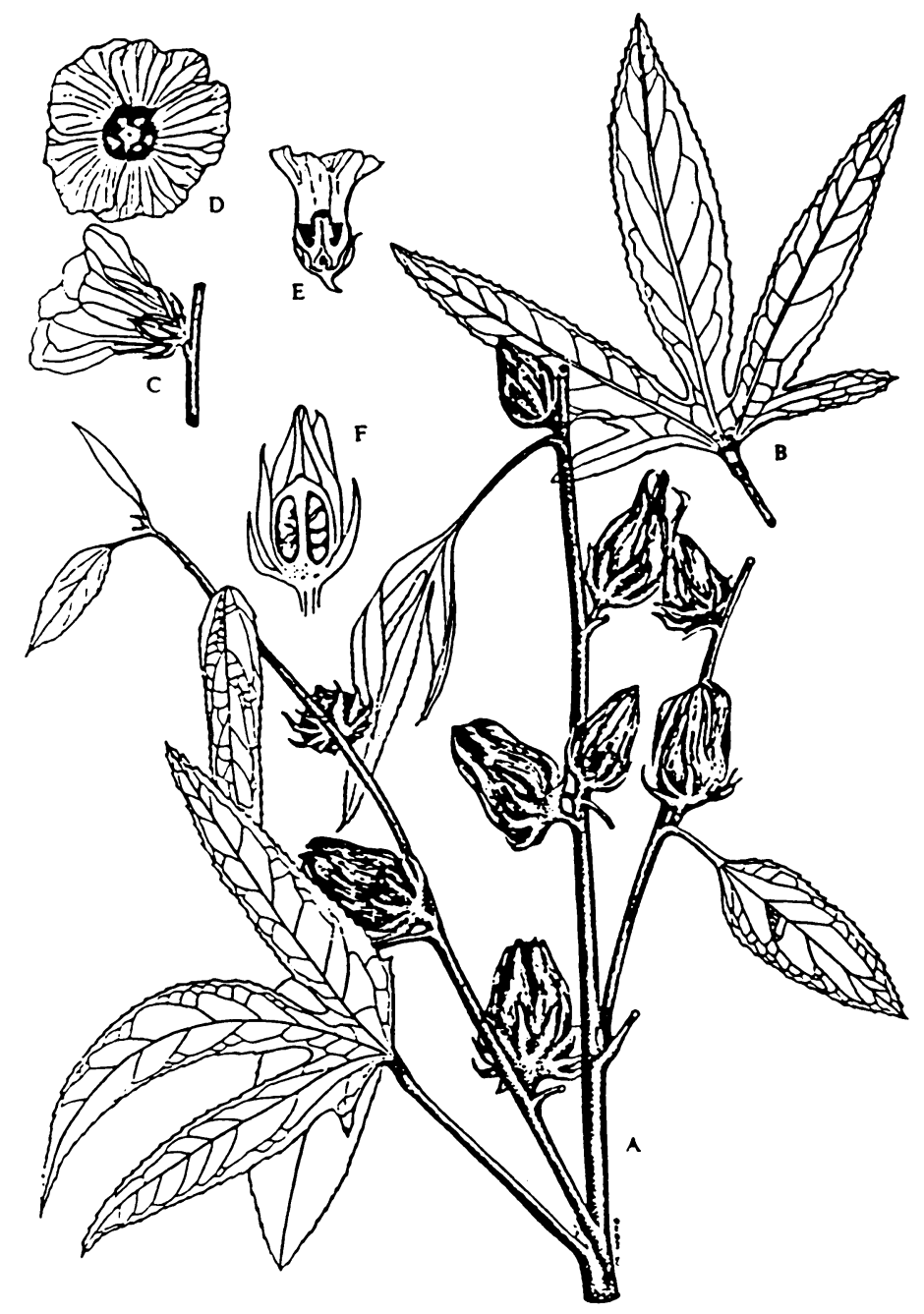

Figuur 2 : Hibiscus sabdariffa L., A. vruchtdragende tak; B. blad;

$C$. zijaanzicht van een bloem; $D$. bovenaanzicht van een bloem;

E. langsdoorsnede van een bloem; F. langsdoorsnede van een vrucht (naar Simoens, 1985) 
In Indonesië wordt de latex aangewend als middel tegen eelten en wratten, als behandeling bij chronische huidaandoeningen en om gezwellen te laten rijpen (Van Giffen, 1924). Dezelfde auteurs geven ook aan dat het melksap door het uitsmeren van melksap op de verwonde plaats doornen, scherven en splinters uit het lichaam drijft. Inlanders gebruiken de plant om beenbreuken te genezen. Zij wrijven de huid in de buurt van de breuk in met het melksap of met de fijngewreven bast omdat zij menen dat dit de beenvorming zal bevorderen. Heyne (1927) geeft als variant van deze behandeling dat de fijngewreven bast op het gebroken been wordt "gebonden".

\subsubsection{Voortplanting}

Zoals zovele andere planten heeft E. tirucalli ook (al of niet vermeende) abortieve eigenschappen (Raymond, 1939). Saha et al. (1961) vermelden dat E. tirucalli-latex een vruchtafdrijvend middel is. Een waterige oplossing heeft eigenschappen die vergelijkbaar zijn met oxytocine (de hormonale stof uit de hypofyse-achterkwab, die de zwangere baarmoeder tot samentrekking brengt).

Bij bepaalde Oostafrikaanse volkeren gebruikt men de latex van E. tirucalli als een remedie tegen sexuele impotentie. In het voormalige Rhodesië wordt het aangewend tegen steriliteit. In Indië wordt hij gebruikt in de behandeling tegen syphilis (Dragendorff, 1898; Watt \& Breyer-Brandwijk, 1962). Volgens Dutta \& Karimullah (1944) moet men hiervoor de latex vermengd met bloem oraal innemen.

\subsubsection{Kanker}

Verse stengeldelen vertonen een antikanker-activiteit en kunnen bepaalde tumoren in omvang doen afnemen (Abbott et al., 1966). In Indië wordt het sap van E. tirucalli gebruikt tegen tumoren, asthma, leucorrhoea en spijsverteringsmoeilijkheden (Baslas \& Gupta, 1983). Volgens Baslas \& Gupta (1983) is ook de wortel werkzaam tegen kanker. De latex daarentegen zou een krachtig tumorverwekkend middel zijn bij muizen (Roe \& Pierce, 1961; geciteerd door Kinghorn, 1979). 


\subsubsection{Andere}

De plant wordt in Indië eveneens gebruikt bij kalveren als diureticum, vermicide (wormdodend middel) en om de leverwerking te stimuleren (Gupta \& Mahadevan (1967) citeren hiervoor Kritikar \& Basu (1935) en Chopra et al. (1956), maar geven niet aan welk deel van de plant gebruikt werd).

In Tanzania gebruikt men de wortel bij de behandeling van slangebeten (Raymond, 1936).

De wortels worden eveneens aangewend als kataplasme (omslag met warm papje tegen verzweringen aan de neus en tegen aambeien). In Indië gebruiken de autochtonen de wortels als een remedie tegen kolieken, asthma en buikpijn (Khan et al., 1987).

Het "sap" van de plant wordt in Indië gebruikt tegen reuma, tandpijn en debiliteit (Dutta \& Karimullah, 1944).

In Rwanda gebruikt men traditioneel E.tirucalli om oogziekten bij dieren te genezen (Balasubramanian \& Egli, 1989).

\subsection{GEBRUIK VAN E, TIRUCALLI ALS VERGIF}

\subsubsection{Bactericide en amoebicide}

Een waterige oplossing van E. tirucalli-latex is een goed middel tegen Staphylococcus aureus, maar niet tegen Escherichia coli (Karel \& Roach, 1951) en heeft eveneens een amoebicidale activiteit tegen Entamoeba histelytica (Dhar et al., 1968).

\subsubsection{Molluscicide}

E. tirucalli kan ook gebruikt worden als middel om weekdieren te doden (molluscicide). 
Vassiliades (1984) gebruikt vers of gedroogd, gemalen of verbrijzeld plantemateriaal om de Lumnaea natalensis-slak (tussenwaard voor Easciola gigantica, die leverbot bij vee veroorzaakt) voor $100 \%$ te doden (aan $0,3 \mathrm{~g}$ materiaal/ $\mathrm{H}_{2} \mathrm{O}$ ).

Tegen de Bulinus guemei-slak (tussenwaard voor een aantal schistosoma's en paramphistomen) is het minder doeltreffend: 45 a $65 \%$ van de diertjes worden gedood bij $0,5 \mathrm{~g} / \mathrm{l}$. De gebruikte testvisjes ondervonden geen hinder van de E. tirucalli- behandeling. Dit laatste punt is belangrijk vermits naast de schadelijke slakjes ook nuttige vissen in het te behandelen water kunnen aanwezig zijn.

Jurberg et al. (1985) gebruikten waterige oplossingen van E. tirucalli-latex om volwassen Biomphalaria glabrata-slakjes te doden. Deze tussenwaard van Schistosoma mansoni werd gedood (LD90) bij concentraties van 85 ppm $(0,0085 \%)$. De toxiciteit voor vissen was van dezelfde grootteorde als die van $\mathrm{CuSO}_{4}$ en het commerciële Bayluscide.

Het natuurlijk produkt op basis van E. tirucalli heeft het voordeel van de prijs. De plant komt endemisch voor in die gebieden waar de geviseerde tussenwaard voorkomt, en wordt er gemakkelijk vermenigvuldigd. Bovendien is de actieve stof gemakkelijk extraheer- en biodegradeerbaar. De slakjes worden niet afgeschrikt door het produkt, zodat ze inderdaad gedood worden en niet wegvluchten.

\subsubsection{Nematicide}

De latex van E. tirucalli blijkt erg toxisch te zijn voor een aantal nematoden. Hoplolaimus indicus, Helicotylenchus indicus en Tylenchus filiformis zijn na $72 \mathrm{u}$ voor $100 \%$ gedood door een 1:1 met gedestilleerd water verdunde latexoplossing. Enkele soorten worden zelfs door lichtere concentraties gedood (Siddiqui et al., 1984). Het is evenwel niet duidelijk welke de fatale factor is die de nematoden doodt.

\subsubsection{Visvergif (icthyotoxicide)}

E. tirucalli wordt door een aantal volkeren als visvergif gebruikt (Fürstenberger \& Hecker, 1977). Ofwel worden de vissen bedwelmd, ofwel gedood. 
Burtt-Davy en Stent (1913) stippen aan dat men voor deze toepassing vooral de schors gebruikt. Volgens Quisumbing (1947) zou de actieve stof euphorbon zijn.

Raymond (1936 en 1939) geeft voorbeelden voor Tanzania. Berhaut (1975) vermeldt het voor Senegal. Watt \& Breyer-Brandwijk (1962) citeren verder voorbeelden voor Indië, Indonesië, Zuid-Oost-Azië en de Filippijnen. Ook Chopra (1933) en Chopra et al. (1941) (Indië), Quisumbing (1947; Filippijnen) en Heyne (1927; Indonesië) vermelden het.

Van Giffen (1924) deed proeven met goudvissen. In een oplossing van $10 \mathrm{mg}$ gedroogd melksap in 1 liter water stierven ze na 40 minuten. Dezelfde auteur citeert ook Boorsma (jaartal niet vermeld) die vond dat een verdunning van 1:500.000 al voldoende was om de goudvissen te bedwelmen.

Bij gebruik als visvergif in stilstaande waters moet men er over waken om achteraf zelf niet in dit water te gaan zwemmen. Dit heeft al meerdere malen tot dodelijke ongevallen geleid (Raymond, 1939).

Kopaczewski (1947) doodde Gambusia-visjes met waterige oplossingen van verse E. tirucalli-latex. De concentraties varieerden van $1 \%$ tot $0,000001 \%$, en de dood trad in na, respectievelijk, 10 tot 100 minuten. Oplossingen met de gekookte latex gaven analoge resultaten. De gedroogde latex $\left(65^{\circ} \mathrm{C}\right)$ bleek minder werkzaam.

\subsubsection{Insecticide}

In Indië gebruikt men E. tirucalli-latex voor de bereiding van insecticides. In Oost-Afrika gelooft men dat de boom muggen afschrikt.

\subsubsection{Andere diersoorten}

Ook andere diersoorten kunnen gedood worden door E. tirucalli.

Berhaut (1975) zegt dat de plant gebruikt wordt tegen ratten. Zij kunnen gedood worden na een orale toediening van $0,4 \mathrm{ml}$ van een $10 \%$-oplossing van latex in water. De oorzaken en symptomen die de dood voor gevolg hebben, gelijken goed op deze beschreven voor de mens (Watt \& Breyer- 
Brandwijk, 1962). Proeven op witte ratten geven $100 \%$ doding 15 minuten na een intra-peritoneale inspuiting met $0,2 \mathrm{ml}$ onverdunde latex (Kopaczewski, 1947).

Kraaien kunnen eerst verdoofd en dan gedood worden door het eten van gekookte rijst waar men nadien latex doorheen gemengd heeft (Burtt-Davy \& Stent, 1913). Men kan de latex ook laten koken tezamen met de rijst (Watt \& Breyer-Brandwijk, 1962).

In het voormalige Kongogebied, evenals in het Soedanese gebied tussen de Kongo (Zairre) en de Nijl, voegen sommige stammen het sap van bepaalde Euphorbia-soorten, waaronder dat van E. tinucalli, aan hun pijlgif toe. Dit melkachtig sap verwekt een hevige prikkeling en ontstekingsverschijnselen op de plaats waar de pijl het lichaam binnendringt. Eens de latex uitgedroogd is, is het gif echter volledig ineffectief (Lewin, 1923).

\subsection{ANDERE GEBRUIKSDOELEINDEN}

Balasubramanian en Egli (1989) vermelden dat E. tirucalli in Rwanda gebruikt wordt als brandstof. $\mathrm{Zij}$ zeggen er niet bij of men hiervoor droge takken gebruikt dan wel een ander plantedeel. Over het mogelijke gebruik van E.tinucalli als energiegewas zal verder ingegaan worden in een tweede artikel in dit tijdschrift.

Wanneer men de plant verbrandt, bekomt men een ruwe vorm van kaliumcarbonaat, de zogenaamde "pearl ash". Die as wordt gebruikt in de traditionele zeepbereiding in Indië (Burtt-Davy \& Stent, 1913; Watt \& Breyer-Brandwijk, 1962).

Latex gemengd met modder kan gebruikt worden om platte daken te maken (Zuid-Afrika; Burtt-Davy \& Stent, 1913), net zoals men in West-Afrika een aftreksel van Parkia biglobosa gebruikt om een betonharde kleibekleding te bekomen (vooral de Tamberma uit Togo en Benin maken hier heel goed gebruik van: ze bouwen hutten met een verdieping waarbij het platform heel stevig moet zijn en het door het gebruik van die natuurlijke verharder ook is). 
Het hout wordt gebruikt als vlothout, omdat het niet vlug aangetast wordt door wormen (Watt \& Breyer-Brandwijk, 1962).

In het volksgeloof neemt men aan dat de E. tinucalli beschermt tegen bliksem-inslag (Senegal; Berhaut, 1975). De Bantoevolkeren planten E. tirucalli om die reden aan op het erf ("rond de kraal").

In de Filippijnen werd de latex gemengd met terpentijn als vernis gebruikt (Henke, 1886). In Zuid-Afrika is er een tijdlang onderzoek gedaan om na te gaan of de harsrijke latex niet kon gebruikt worden als basis voor commerciële vermis, om zo de hoge kostprijs van de tirucalli-rubberwinning te compenseren.

Spoon (1928) citeert berichten (sic) uit niet nader omschreven referenties dat het melksap zou kunnen gebruikt worden voor de bereiding van roestwerende verf. Steeds volgens Spoon (1928) wist men al in 1870, uit experimenten in Natal, dat ijzer bestreken met Euphorbia-latex roestvrij kan gemaakt worden. Twee anonieme bronnen (Anoniem, 1927a en b) refereren wellicht naar dezelfde waarnemingen van 1870 , en voegen er aan toe dat de aldus gebruikte Euphorbia-latex "vrij is van blarentrekken, van barsten en van afschilferen". Niettegenstaande deze positieve eigenschappen heeft men in die periode tevergeefs getracht kapitaalkrachtige mensen te vinden om die vondst te exploiteren (Anoniem, 1927a).

Spoons artikel wil de interesse duidelijk terug opwekken en eindigt met de zin: "misschien is men ditmaal gelukkiger". Anoniem (1927b) merkt ook nog op dat "men op de Euphorbia-latex als grondstof voor rubber misschien wat aan te merken mag hebben, maar als roestwerende stof kan zij nog wel eens heel deugdelijk blijken te zijn" en eindigt met een hoopvolle noot: "Zuid-Afrika houdt op den Euphorbia nauwlettend het oog gericht"...

Het lijkt echter weinig waarschijnlijk dat deze verf ooit op commerciële schaal is geproduceerd, vermits er in de litteratuur geen verder gewag meer gemaakt wordt van enige activiteit in deze sector.

De latex bevat heel veel hars (tot $85 \%$ ) die eruit geëxtraheerd kan worden met gedenatureerde alcohol en aceton. De kristallisatie van dat hars uit de oplossing is een serieus nadeel voor industrieel gebruik maar een gepaste 
voorbereiding en menging met het juiste oplosmiddel verhoogt de stabiliteit als vernis (Bulletin, 1944) zodanig dat een commerciële verwerking mogelijk wordt naar linoleum, leerindustrie en geolied doek toe.

Karimullah en Gopalachari (1949) konden een visceuze fractie destilleren uit het hars middels een overhete stoom $\left(250^{\circ} \mathrm{C}\right)$ en met het residu op basis van lijnzaadolie een vernis maken die bevredigende eigenschappen gaf. Beide fracties bleken op te lossen in benzeen, terpentijn en lijnolie. Verdere eigenschappen van het hars worden gegeven door beide voornoemde auteurs.

Stienswat laat in een persoonlijke mededeling weten dat methylalcoholextractie van E. tirucalli-materiaal een extract geeft waarin ongeveer zeventig procent hexosen zitten. Fermentatie via Saccharomyces cerevisiae produceert alcohol die als brandstof kan dienen.

\section{BESLUIT}

Zoals uit het voorgaande blijkt, zijn er verschillende gebruiksdoeleinden voor E. tirucalli mogelijk. Dit lijkt een constante te zijn voor heel wat minder gekende planten uit Afrika. Recent onderzoek heeft aangetoond dat er veel planten zijn die potentieel heel wat mogelijkheden in zich hebben en er gewoon om vragen om eens op grote schaal geteeld en benut te worden. Een hele reeks planten bevatten een aantal actieve stoffen die ze ook voor de industrie heel interessant maken.

Wat ook opvalt, is dat doorheen de verschillende continenten en binnen de continenten in verschillende landen en volkeren, eenzelfde plant dikwijls voor dezelfde doeleinden gebruikt wordt. Blijkbaar is de nieuwsgierigheid van de mens niet begrensd (woordspeling is opzettelijk)... Omgekeerd, kunnen we nog heel wat leren van de zogenaamde primitieve beschavingen.

\section{Bedankingen.}

De auteur wenst ir. Reinhilde Blondeel te bedanken voor het tikwerk van het oorspronkelijk manuscript. Hij is ook schatplichtig aan dr. Maria Morlion en dr. Gert Laekeman voor constructieve kritiek en bijkomende informatie bij het herlezen van de tekst. 


\section{BIBLIOGRAFIE}

Abbott, B.J., Hartwell, J.L., Iltis, H.H., Kupchan, S.M., Leiter, J., Perdue, R.E. \& Schepartz, S.A. (1966). Screening data from the cancer chemotherapy national service center screening laboratories. XXXVI. Plant extracts. Cancer Research, 26 (9), 1131 - 1277.

Anoniem (1927a). Euphorbia-latex. Zuid-Afrika, 4, 43.

Anoniem (1927b). Weekberichten. Algemeen Landbouwweekblad voor Nederlandsch-Indië, $11,1111$.

Badhwar, R.L., Nayar, S.L. \& Chopra, I.C. (1946). Indian plants liable to produce dermatitis. The Indian Journal of Agricultural Science, 15, 155 -171.

Balasubramnanian, V. \& Egli, A. (1989). The role of agroforestry in the farming systems in Rwanda with special reference to the Bugesera-Gisaka-Migongo (BGM) region. In: Nair, P.K.R., Agroforestry Systems in the Tropics. Kluwer, Dordrecht, 333 - 352.

Baslas, R.K. \& Gupta, N.C. (1983). Chemical investigation of Indian medicinal plants possessing anticancer activity: roots of Euphorbia tinucalli Linn. Indian Journal of the Chemical Society, $60(5), 506$ - 507.

Berhaut, J. (1975). Flore illustrée du Sénégal. In: Ministère du Développement Rural. Dicotylédones. Tome III. Connaracées - Euphorbiacées. Direction des Eaux et Forêts, Dakar, 634 p.

Bradley, P.N., Chavangi, N. \& Van Gelder, A. (1985). Development Research and energy planning in Kenya. Ambio, 14 (4/5), 228 - 235.

Bulletin (1944). Eupherbia tincalli resin from South Africa. Bulletin of the Imperial Institute, $42,1-13$.

Burtt-Davy, J. \& Stent, S.M. (1913). Fodder plants for the dry bushveld. Agricultural Journal of the Union of South Africa, 6,66 - 79.

Chopra, R.N. (1933). Indigenous drugs of India. Their medical and economic aspects. Art Press, Calcutta, 988 p.

Chopra, R.N., Badhwar, R.L. \& Nayar, S.L. (1941). Insecticidal and piscicidal plants of India. Journal of the Bombay Natural History Society, 42, 854 - 902.

Chopra, R.N., Nayar, S.L. \& Chopra, I.C. (1956). Glossary of Indian medicinal plants. Council of Scientific and Industrial Research, New Delhi, ? p.

Davidson, A. \& Rochford, D. (1976). House plants, cacti and succulents. Hamlyn, London, $192 \mathrm{p}$. 
De Conno, E., Capalbi, S. \& Fruitier, L. (1929). Sul latice di Euphorbia tinucalli, Candelabro ed Abyssinica. Annali Chimica Applicada Roma, 18, 540 - 549.

Dey, A.C. \& Fernandez, R.R. (1968). Hedges and hedge-plants in India. Indian Forestry Leaflet, $189,29 \mathrm{p}$.

Dhar, M.L., Dhar, M.M., Dhawan, B.N., Mehrotra, B.N. \& Ray, C. (1968). Screening of Indian plants for biological activity: part I. Indian Journal of Experimental Biology, 6, 232 - 247.

Dragendorff, G. (1898). Die Heilpflanzen der Verschiedenen Völker und Zeiten. Ihre Anwendung, wesentliche Bestandteile und Geschichte. Enke, Stuttgart, 386 - 387.

Dutta, N.L. \& Karimullah, A. (1944). Chemical examination of the dried latex from Euphorbia tinucalli. Journal of Scientific and Industrial Research, 3, 212.

Fürstenberger, G. \& Hecker, E. (1977). New highly irritant euphorbia factors from latex of Euphorbia tirucalli L. Experientia, 33, 986 - 988.

Gupta, R.K. \& Mahadevan, V. (1967). Chemical examination of the stems of Euphorbia tinucalli. Indian Journal of Pharmacy, 29 (5), 152 - 154.

Henke, G. (1886). Ueber den Milchsaft einiger Euphorbiaceen. Archiv der Pharmacie, 24 (17), 729 - 759.

Heyne, K. (1927). De nuttige planten van Nederlandsch Indië. Buitenzorg, Indonesië, 2, 964 $-965$.

Jurberg, P., Cabral Neto, J.B. \& Schall, V.T. (1985). Molluscicide activity of the avelos plant (Euphorbia tinucalli L.) on Biomphalaria glabrata, the mollusc vector of schistosomiasis. Mem. Inst. Oswaldo Cruz, 80 (4), 423 - 427.

Karel, L. \& Roach, E.S. (1951). A dictionary of antibiosis. Columbia University Press, New York, 119.

Karimullah, A. \& Gopalachari, R. (1949). Chemical examination of the dried latex from Euphorbia tinucalli. Joumal of Scientific and Industrial Research, 8b, (5), 89 - 91.

Kerharo, J. \& Adam, J.G. (1974). La pharmacopée sénégalaise traditionelle. Plantes médicinales et toxiques. Vigot, Parijs, $869 \mathrm{p}$.

Khan, A.Q., Ahmed, Z., Kazmi, N. \& Malik, A. (1987). Further triterpenes from the stem bark of Euphorbia tirucalli. 577 (Bron niet verder te specifiëren).

Kinghom, A.D. (1979). Characterization of an irritant 4- deoxyphorbol diester from Euphorbia tirucalli. Journal of Natural Products, 42 (1), 112 - 115. 
Kopaczewski, W. (1947). Etude physico-chimique du latex. V. Le latex d'Euphorbia tinucalli. Bulletin de la Société de Chimie Biologique, 10 - 12,924 - 926.

Kritikar, K.R. \& Basu, B.D. (1935). Indian medicinal plants, vol.3. Basu, Allahabad, 2201 p.

Leach, L.C. (1973). Euphorbia tirucalli L.: its typification, synonymy and relationships, with notes on "Almeidina" and "Cassoneira". Kirkia, 9, 69 - 87.

Lewin, L. (1923). Die Pfeilgifte. Johann Ambrosius, Leipzig, 518p.

Mitchell, J. \& Rook, A. (1979). Botanical dermatology. Plants injurious to the skin. Greengrass, Vancouver, $787 \mathrm{p}$.

Moll, E.J. (1978). A new method of collecting Euphorbia latex. Veld en Flora, 64 (1), 2 - 4.

Quisumbing, E. (1947). Philippine plants used for arrow and fish poisons. Philippine Journal of Science, 7, $127-177$.

Raymond, W.D. (1936). The poisonous effects of some local species of Euphorbia. East African Medical Joumal, 12, 369 - 374.

Raymond, W.D. (1939). Native poisonous and native medicines of Tanganyika. The Journal of Tropical Medicine and Hygiene, 42, 295 - 303.

Saha, J.C., Savini, E.C. \& Kasinathan, S. (1961). Ecbolic properties of Indian medicinal plants. Indian Joumal of Medical Research, 49 (1), 130 - 151.

Siddiqui, M.A., Haseeb, A. \& Alam, M.M. (1984). Toxicity of plant latex to some plant parasitic nematodes. National Academy of Science Letters, 7 (1), 1 - 2.

Simoens, P. (1985). Morfologie, fysiologie en teelt van Hibicus sabdariffa L. Werk van einde studiën, Rijksuniversiteit Gent, Coupure Links, 653, B- 9000 Gent, 157p.

Spoon, W. (1928). Berichten van het Handelsmuseum van het Koloniaal instituut, Amsterdam, $34,3-14$.

Van Damme, P. (1989). Studie van Euphorbia tinucalli L., morfologie, fysiologie, teeltvoorwaarden. Doctoraal proefschrift, Rijksuniversiteit Gent, Coupure Links, 653, B-9000 Gent, $375 \mathrm{p}$ (+ bijlagen).

Van Giffen, H.J. (1924). Vergiftiging met het melksap van Euphorbia tirucalli L. Pharmacologisch Tijdschrift van Nederlandsch-Indiè, 1 (12), 376 - 387.

Vassiliades, G. (1984). Note sur les propriétés molluscicides de deux Euphorbiacées: Euphorbia tinucalli et Jatropha curcas. Essais en laboratoire. Revue de Médecine Vétérinaire des Pays Tropicaux, 37 (1), 32 - 34. 
Watt, J.M. \& Breyer-Brandwijk, M.G. (1962). The medicinal and poisonous plants of southern and eastern Africa. Livingstone, Edinburgh, 415 - 417.

White, A., Dyer, R.A. \& Sloane, B.L. (1941). Euphorbia tinucalli. The succulent Euphorbieae of Southern Africa, $101-106$. 